\title{
Letramento acadêmico: leituras de uma experiência
}

\author{
Sebastião Silva Soares \\ Universidade Federal do Tocantins
}

\begin{abstract}
Resumo
Este trabalho apresenta uma experiência ${ }^{1}$ que buscou promover a prática do gênero acadêmico artigo científico à luz dos estudos dos Novos Letramentos dos autores Street (2014), Kleiman (2008) e Fischer (2008). O público-alvo foi 60 acadêmicos do Curso de Licenciatura em Educação do Campo na Universidade Federal do Tocantins. A proposta surgiu tanto de observações em sala de aula, como também das percepções dos docentes do curso. A metodologia baseou-se no desenvolvimento da prática da leitura, da escrita e reescrita por meio de atividades de tutoria do professor das disciplinas Gêneros acadêmicos I e II em classes e extraclasse. A ação proporcionou que os acadêmicos compreendessem a leitura e a escrita não como mera exigência da universidade, mas sim como uma situação comunicativa, uma prática social e ideológica.
\end{abstract}

Palavras - Chaves: Letramento acadêmico. Ensino Superior. Artigo científico.

\begin{abstract}
This paper presents an experiment that sought to promote the practice of the scientific article genre in light of the studies of the New Literacy by Street (2014), Kleiman (2008), and Fischer (2008). The public was 60 undergraduates in a teaching course in education at the Federal University of Tocantins. The proposal came from observations in the classroom, as well as from the teachers' perceptions of the course. The methodology was based on the development of the practice of reading, writing and rewriting through teacher mentoring activities in class and out-of-class in the subject of Academic Genres I and II. The action helped the academics to understand reading and writing not as a mere requirement of the university but as a communicative situation, a social and ideological practice.
\end{abstract}

Keywords: Academic literacy. Higher education. Scientific article.

\section{INTRODUÇÃO}

O desenvolvimento das práticas da leitura e da escrita nos últimos anos tem sido foco de diversos estudos, em âmbito nacional e internacional, principalmente no contexto da educação superior. Nesses estudos, Street (2014), Fischer (2008/2010), Gee, (1999), Lea e Street (1998), Bezerra (2012), Marinho (2010), Fiad (2015), Araujo (2016), Santos, (2017) têm buscado desvelar e analisar os processos de aquisição e desenvolvimento das atividades de leitura e de escrita dos acadêmicos no espaço universitário.

\footnotetext{
${ }^{1}$ Compreendemos neste trabalho a experiência como a continuidade de outras experiências, pois experiência e interação são fatores interconectados, consequentemente, a experiência se torna uma ação pessoal e social (CONNELLY; CLANDININ, 2015).
} 
A prática da leitura e da escrita, no decorrer da história da educação, foi e é alvo de críticas em relação ao desempenho dos alunos nas atividades escolares e exames externos (SOARES, 2004). Por outro lado, o espaço universitário exige competências e habilidades linguísticas dos acadêmicos que superam os conhecimentos construídos na educação básica, realidade essa que se torna um dilema para muitos estudantes que têm o primeiro contato com o meio universitário.

$\mathrm{Na}$ universidade, os acadêmicos devem apresentar bom desenvolvimento de leitura e produção escrita, pois a cada momento são solicitadas atividades que necessitam maior domínio de linguagem, compreensão da função e elaboração de diversos gêneros textuais, tais como fichamento, resenha, resumo e artigo científico. Segundo a literatura supracitada, os alunos devem demonstrar habilidades linguísticas de leitura e de escrita já construídas no seu processo formativo vital e escolar. Em outras palavras, "é preciso conhecer e dominar os diversos tipos de gêneros para que a comunicação verbal/escrita se estabeleça de forma coerente e eficaz”. (ORTEGA; DINIZ, 2005, p. 04).

Entretanto, nem sempre isso acontece, principalmente diante das dificuldades na prática da leitura e da escrita que os estudantes apresentam de anos anteriores de escolarização, bem como a falta de interesse, o não incentivo dos professores formadores que, às vezes, não utilizam metodologias significativas para o trabalho da leitura e da escrita e a falta de uma política linguística nas escolas e nas propostas de ensino do governo (FISCHER, 2008). É perceptível, no contexto da sala de aula universitária, o desencanto de muitos estudantes pelas atividades propostas pelos professores, particularmente no que diz respeito às práticas da leitura e da escrita.

É observável que a maioria dos alunos que chega aos bancos da universidade, quando vai produzir um texto e/ou fazer uma leitura, caracteriza esses momentos como espaços/tempos de medo, insegurança e desestímulo, pois o contexto dos livros científicos, dos periódicos, anais de evento, congressos, seminários, mesas-redondas não corresponde em prática aos outros domínios discursivos em que os acadêmicos foram e/ou estão inseridos.

Dessa forma, infere-se que a prática da leitura e da escrita no âmbito da universidade deve ser um momento propício de formação humana, intelectual e profissional dos acadêmicos, especificamente com a integração do ensino, da pesquisa e extensão. Por outro ângulo, pode ser fator de desestímulos e evasão acadêmica, visto que muitos estudantes não conseguem corresponder às exigências acadêmicas, em particular na produção da leitura e da escrita científica (SANTOS, 2017). 
Entendemos que essa realidade é ampliada quando lidamos com alunos do ensino superior advindos das escolas do campo, que sofreram e sofrem com a ausência de políticas educacionais do/no e para o campo (SOUZA, 2006). Mas isso "não quer dizer que o estudante não sabe ler e escrever de uma maneira geral, mas sim que não operaria com uma forma discursiva específica - o discurso acadêmico - pela qual a faculdade se identifica e é identificada" (BRITTO, 2003, p. 187).

Nessa linha de pensamento, este trabalho apresenta uma experiência que buscou promover a prática da produção do gênero acadêmico artigo científico no contexto do ensino superior à luz dos estudos dos Novos Letramentos. Buscamos desenvolver uma metodologia que contribuísse com o planejamento e a elaboração do gênero acadêmico artigo científico para além da dimensão prescritiva do gênero na formação de futuros professores. O públicoalvo participante das atividades foi 60 acadêmicos do Curso de Licenciatura em Educação do Campo, na Universidade Federal do Tocantins, Campus Arraias - Brasil.

De acordo com essa breve introdução e o objetivo geral deste artigo, o texto foi organizado em duas partes: na primeira, apresentamos uma breve reflexão teórica sobre o letramento, com destaque para o letramento acadêmico-científico, que subsidiaram a construção do desenvolvimento da experiência em foco. Posteriormente, são apresentados os materiais e métodos empregados no estudo; por fim, os resultados e considerações.

\section{LETRAMENTO ACADÊMICO E A PRODUÇÃO DA LEITURA E DA ESCRITA NO ÂMBITO DA UNIVERSIDADE}

O termo letramento, segundo Soares (2004), surgiu há pouco mais de duas décadas. Este foi empregado para designar o desenvolvimento e as habilidades da leitura e da escrita dos indivíduos, fato que supera a dimensão da aquisição e decodificação do sistema linguístico (alfabético e ortográfico), característica observada no contexto da alfabetização.

Com o termo letramento, tem-se a ampliação da compreensão das práticas sociais da leitura e da escrita realizada pelo homem nos diversos contextos sociais. Isso porque, com o desenvolvimento humano no decorrer dos tempos e a inserção dos novos modos de produção, principalmente com as tecnologias da informação, as práticas centradas na produção da escrita e da leitura superam a dimensão da mera decodificação do alfabetizar. Todavia, a autora ressalta:

Por outro lado, também é necessário reconhecer que, embora distintos, alfabetização e letramento são interdependentes e indissociáveis: a alfabetização só tem sentido quando desenvolvida no contexto de práticas sociais de leitura e de escrita e por 
meio dessas práticas, ou seja, em um contexto de letramento e por meio de atividades de letramento; este, por sua vez, só pode desenvolver-se na dependência da e por meio da aprendizagem do sistema de escrita. (SOARES, 2004, p. 97).

Dessa maneira, embora o letramento seja um termo distinto da alfabetização, Soares (2004) ressalta a importância de compreender ambos os processos como indissociáveis e interdependes, pois é necessário inserir os alunos no processo de conhecimento do sistema da escrita num contexto de letramento, no qual as práticas da leitura e da escrita sejam construídas em âmbito real e significativo. Sendo assim, "enquanto a alfabetização se ocupa da aquisição da escrita por um indivíduo, ou grupo de indivíduos, o letramento focaliza os aspectos sócio-históricos da aquisição de um sistema escrito por uma sociedade" (TFOUNI, 1995, p. 20).

No caso mais específico do letramento, os estudos buscam desenvolver análises mais amplas (dimensão política, social, cultura e ideológica) das práticas da leitura e da escrita nos diversos domínios situados e discursivos (KLEIMAN, 2008). Com esse evento é possível desenvolver um olhar analítico e constitutivo da linguagem, focado nas relações de poder construídas entre os autores sociais. É possível afirmar que temos, com a reflexão do letramento, a valorização do espaço cultural e da trajetória formativa dos alunos como proposição do desenvolvimento e habilidades linguísticas apresentadas na vida social segundo práticas socioculturais.

Marcuschi (2007) argumenta que o letramento é o uso da leitura e da escrita como processo histórico, social e cultural. Para o autor, o letramento diz muito das crenças, valores e funções atribuídos ao uso da leitura e da escrita, conforme o contexto de produção e recepção discursivo, sendo um bem social fundamental de sobrevivência do homem no mundo contemporâneo.

Nessa perspectiva, os autores têm buscado compreender o letramento numa perspectiva sociocultural e múltipla, pois a linguagem é uma esfera social e discursiva, construída por valores e ideologias dominantes de um contexto histórico e específico (BAKHTIN, 1986). Consequentemente, as práticas de letramento são produtos de um povo, de uma cultura, de uma história e do discurso (STREET, 2014).

Desse modo, as práticas letradas vão além das normatizadas e prescritas pelo espaço escolar. Diante das diversas práticas letradas existentes na sociedade, Street (2014) faz a distinção de dois modos de pensar as práticas de letramento: o modelo "autônomo" e o modelo “ideológico". O primeiro modelo pressupõe um modo único e universal 
(instrumentalização) do letramento; já no segundo modelo encontramos uma visão mais ampla deste, como prática social e culturalmente situada.

O letramento ideológico não nega as práticas e as investigações do letramento autônomo, pois é necessário compreender que os "correlatos cognitivos da aquisição da escrita na escola devem ser entendidos em relação às estruturas culturais e de poder que o contexto de aquisição da escrita na escola representa" (KLEIMAN, 2008, p. 39). No contexto específico das práticas de leitura e de escrita na universidade, Lea e Street (1998) argumentam que o letramento na universidade pode ser compreendido em três perspectivas: a primeira compreende o letramento como ações individuais e cognitivas, em particular as habilidades linguísticas dos alunos, sem levar em consideração os conhecimentos prévios anteriores desses estudantes antes de ingressar no ensino superior.

A segunda perspectiva, denominada pelos autores de "socialização acadêmica", diz respeito à inserção dos alunos para conhecer e lidar com os diversos gêneros textuais que circulam no espaço da universidade. Esta tem a finalidade de garantir aquisição de habilidades e competências nas atividades de leitura e de escrita que circulam na esfera acadêmica, com destaque para o papel dos professores nesse processo como agentes de letramento e mediadores de saberes.

No último caso, os autores compreendem o letramento acadêmico no plural, reconhecendo as dimensões sociais, culturais e de sentidos estabelecidos na formação dos alunos e identidades sociais. Assim, cada modelo apresentado não visa estabelecer uma relação hierárquica, pois o objetivo maior dos modelos é mapear e fortalecer, de forma híbrida e concomitante, as práticas de leitura e de escrita na universidade na formação dos acadêmicos como sujeitos históricos e ser social.

Fischer (2008) argumenta que o letramento acadêmico é um movimento de pensar, ler e escrever determinado de um contexto social. Para a autora, a partir dos estudos de Klemp (2004), o desenvolvimento do letramento acadêmico pode representar as interações dos alunos com os diversos gêneros orais e escritos que circulam no espaço universitário. Consequentemente, sintetiza:

Muitos dos eventos de letramento presentes no meio acadêmico são recorrentes de outros contextos sociais, sejam em atividades orais ou escritas. Logo, não dá para negar que o ensino superior, incluindo professores e alunos, tem o compromisso de destinar esforços a atividades cujas habilidades estejam subjacentes ao letramento acadêmico. (FISCHER, 2008, p. 181). 
Nessa perspectiva, pensar o letramento acadêmico como prática social e cultural demarca eventos que visem à análise dos sentidos e compreensões da leitura e da escrita como artefatos ideológicos e de relações de poder. Em consequência disso, compreende-se a formação linguística dos alunos como o uso da língua socialmente situado (BAKHTIN, 1986). Desse modo, pensar o letramento acadêmico nos direciona a compreender os eventos de leitura e de escrita que permeiam a formação linguística dos alunos acadêmicos por meio dos diversos gêneros textuais que circulam na universidade, pois "é impossível se comunicar a não ser por algum gênero, assim como é impossível se comunicar verbalmente a não ser por algum texto" (MARCUSCHI, 2002, p. 22).

Dessa maneira, o letramento acadêmico é construído por meio de gêneros textuais que circulam na universidade. Todavia, essa prática, na maioria das vezes, fica centrada apenas numa disciplina ou perspectiva prescritiva do estudo da língua. Existem, segundo a literatura, poucas práticas que visam promover o letramento acadêmico como processo científico, crítico e criativo na formação dos alunos. Para Bezerra (2012, p. 258):

\footnotetext{
Os letramentos acadêmicos se constituirão, essencialmente, como sinônimo de letramentos em gêneros textuais próprios do meio acadêmico, considerando-se não só o processo de aquisição de habilidades de leitura e escrita, nem a mera socialização na cultura universitária, mas fundamentalmente a negociação e a construção da identidade do aluno como membro e participante autorizado dessa/nessa cultura.
}

Para o autor, analisar os eventos de letramento acadêmico é ampliar a compreensão da leitura e da escrita como instâncias discursivas e de legitimação de poder. Por meio dos letramentos acadêmicos, os alunos devem ir além da socialização da cultura universitária, é necessário compreendê-los como sujeitos participantes e autores de uma história.

Destarte, os gêneros acadêmicos (fichamento, resumo, resenha, artigo científico, dentre outros), além de serem textos que emergem no contexto da universidade, tornam-se também mecanismos discursivos que permitem a inserção dos alunos nas práticas de letramento e que ativam as identidades sociais e culturais em dado contexto (GEE, 1999).

\section{METODOLOGIA DA EXPERIÊNCIA E SEUS SUJEITOS}

O público-alvo participante desta experiência envolveu 60 acadêmicos do Curso de Licenciatura em Educação do Campo, na Universidade Federal do Tocantins, Campus Arraias - Brasil. A metodologia empregada baseou-se no desenvolvimento da prática da 
leitura, da escrita e reescrita por meio de atividades de tutoria do professor das disciplinas Gêneros Acadêmicos I e II em classes e extraclasse.

Buscamos desenvolver com os acadêmicos um trabalho interdisciplinar com a valorização dos saberes da trajetória de vida e formação escolar. As atividades foram organizadas em dois semestres do curso. As ementas das disciplinas supracitadas têm como propósito a: "Definição de gênero discursivo. Funcionalidade dos gêneros discursivos. Gêneros discursivos e tipos de texto. Critérios para a caracterização de gêneros discursivos. Gêneros discursivos acadêmicos" (UFT/PPC, 2014, p. 50).

Todavia, embora as ementas das disciplinas apresentem aspectos mais direcionados para o reconhecimento e funcionalidade dos gêneros acadêmicos, desenvolvemos com os alunos atividades alicerçadas nos estudos dos novos letramentos (STREET, 2014), a fim de compreender a prática da leitura e da escrita como eventos socioculturais para além da socialização acadêmica. Isso porque o próprio curso de Licenciatura em Educação do Campo apresenta características que busca promover a emancipação crítica dos estudantes, em particular pela luta dos movimentos sociais em defesa de uma educação pública e de qualidade social para os povos do campo:

\footnotetext{
A base fundamental de sustentação da Educação do Campo é que o território do campo deve ser compreendido para muito além de um espaço de produção agrícola. O campo é território de produção de vida; de produção de novas relações sociais; de novas relações entre os homens e a natureza; de novas relações entre o rural e o urbano. (UFT/PPC, 2014, p. 21).
}

Assim, os eventos de letramento acadêmico foram desenvolvidos no período de 2014/02 ao 2015/01, num contexto dialógico e cultural, marcado pela presença de rupturas e transformação social de jovens e adultos que sofrem com a falta de políticas públicas para o povo no/do e para o campo (ARAUJO, 2016). Nesse sentido, a produção do trabalho artigo científico com o tema "educação do campo e formação de professores" foi o resultado da soma das diversas experiências que os acadêmicos construíram no processo da disciplina, diálogo das disciplinas e pelas experiências de vida como sujeitos sociais.

Para a produção inicial do artigo científico, os acadêmicos foram orientados a seguir elementos básicos que compõem a estrutura do artigo científico, tais como: título, resumo, palavras-chave, introdução, metodologia, desenvolvimento e conclusão. Devido à natureza deste trabalho, apresentaremos no próximo tópico trechos extraídos dos resumos 
presentes nos artigos produzidos pelos acadêmicos, em grupo, como resultado final das atividades.

\section{A EXPERIÊNCIA NARRADA E SEUS RESULTADOS}

Para o desenvolvimento da experiência em foco, inicialmente, apresentamos aos acadêmicos textos de apoio e vídeos que abordavam a temática. Realizamos debates em grupo com o objetivo principal de promover a reflexão sobre a importância da leitura e da escrita. Como exemplo, podemos citar o curta Vida Maria, com a direção de Márcio Ramos, lançado em 2006, que retrata a importância da escrita para as Marias, personagens do curta.

Realizada essa etapa, buscamos perceber os conhecimentos e saberes que os acadêmicos apresentavam sobre os gêneros acadêmicos. Para tal propósito, organizamos com a classe debates, por meio de rodas de conversas em torno das temáticas abordadas nos filmes e as dimensões sobre a leitura e escrita como práticas sociais na vida dos alunos. Posteriormente, trabalhamos em classe com textos que discorriam sobre o ato social da leitura, os níveis de leitura e a produção de textos na perspectiva de gêneros textuais no ensino (MARCUSCHI, 2002).

Para isso, buscamos trabalhar em sala e nas comunidades com diversos gêneros textuais (resumos, resenhas, fichamentos) que abordassem a produção da leitura e da escrita, a fim de demonstrar aos acadêmicos que a produção de um gênero textual deve ir além de estrutura formal e normativa da língua, pois defendemos que "a língua materna - sua composição vocabular e sua estrutura gramatical - não chega ao nosso conhecimento a partir do dicionário e gramática, mas de enunciações concretas” (BAKHTIN, 2003, p. 283).

Na etapa seguinte das atividades, organizamos um breve diagnóstico na turma sobre o conteúdo trabalhado ${ }^{2}$ com os alunos, com o objetivo principal de realizar um levantamento do conhecimento desenvolvido no processo. Feito isso, foram apresentados aos estudantes diversos gêneros acadêmicos que fazem parte da vida universitária. Nesse caso, apresentamos dados referentes à etapa da produção do artigo científico. Cada encontro dessa experiência foi organizado por unidade.

Na primeira unidade, foram trabalhados em classe os princípios teóricos do artigo científico. Foi desenvolvida com os alunos atividade de leituras e escritas sobre o artigo

\footnotetext{
${ }^{2}$ Os conteúdos abordados nas disciplinas estavam relacionados à compreensão dos gêneros acadêmicos, o desenvolvimento de competências e habilidades linguísticas na produção do texto acadêmico e revisão das normas técnicas da Associação Brasileira de Normas Técnicas (ABNT).
} 
científico na universidade, bem como as possibilidades e limitações do gênero na formação dos acadêmicos. Na segunda unidade da experiência, os acadêmicos desenvolveram uma formação prática do conteúdo mencionado na primeira unidade. Podemos dizer que os alunos iniciaram nessa etapa o processo de socialização sobre os textos lidos, o planejamento e a organização do artigo científico. Como foram muitos textos, o trabalho foi divido em partes, respectivamente, pelo professor.

A primeira parte, referente às correções dos trabalhos escritos, foi realizada entre os membros de cada grupo (pré-organizado na turma), por meio de oficina textual; e a outra parte, em atividades extraclasses. Concluída a etapa, os acadêmicos receberam os textos para análise, e depois o grupo se reunia novamente em oficinas para fazer as alterações e sugestões apontadas nos textos na correção do docente. No outro bloco, os textos produzidos foram novamente analisados pelo professor em classe e extraclasse.

Nesse sentido, o objetivo de cada etapa foi inserir os alunos no universo do discurso acadêmico para além da compreensão da língua como um sistema neutro. É possível dizer que, ao ler e discutir os textos com os alunos, o professor buscou promover a leitura horizontal do texto, de modo a permitir a compreensão da leitura e da escrita como práticas socioculturais, pois entendemos que é importante e necessário:

Convidar esses alunos a interrogar as práticas acadêmicas de letramento das quais eles participam, buscando compreender como se constituem essas práticas, desenhando um quadro mais complexo de questões relacionadas, sim, a habilidades linguísticas, mas, sobretudo a dispositivos que refletem relações de poder, disputas e violência simbólica (MARINHO, 2010, p 06).

Nesse ângulo, os alunos desenvolveram diversos gêneros acadêmicos, dentre eles: o fichamento, o resumo e a resenha para chegar à construção do artigo científico. Para ilustrar a experiência narrada, apresentamos, a seguir, quatro exemplos retirados dos resumos extraídos $^{3}$ dos artigos produzidos pelos acadêmicos durante as atividades.

\section{Resumo 01}

No presente artigo, procuramos abordar o que é Educação do Campo, analisando os principais marcos de sua trajetória e a formação de professor para a Educação do Campo no Brasil, uma vez que esta passou a ocupar espaço no cenário educacional brasileiro, nos últimos quinze anos através da luta constante dos movimentos sociais, principalmente com as reivindicações do MST - Movimento dos trabalhadores Sem Terra. Buscamos entender o histórico da educação para/no campo partindo dos princípios que desencadearam em um processo nacional de luta pela garantia de seus direitos. Buscamos abordar as diversas fases enfrentadas e alcançadas na

\footnotetext{
${ }^{3}$ Os resumos apresentados foram selecionados a partir dos trabalhos que o professor orientou via e-mail, sendo assim, são versões preliminares dos trabalhos finais recebidos em classe.
} 
educação nos movimentos sociais do campo em alguns períodos históricos brasileiros. Desse modo, visamos compreender a complexidade nas lutas de classes e as dificuldades encontradas dentro e fora do campo na construção de um modelo de educação para o campo e a importância de se formar educadores para/do campo, entendendo os diferentes sujeitos coletivos que atuam no campo e nos movimentos sociais; que lutam por uma educação que atenda às demandas dos trabalhadores rurais e suas subjetividades como saberes essenciais na articulação de projetos educacionais que levem em conta suas culturas, características, necessidades e sonhos. Objetivamos o entendimento e ampliação dos conhecimentos sobre a trajetória da Educação do Campo, buscando trazer informações para as comunidades dos acadêmicos do curso de educação do campo e a todos que interessarem ampliar seus conhecimentos, uma vez que conhecer a construção desse modelo educacional nos faz entender diferentes diversidades existentes no campo, como os saberes desses sujeitos servem de bases para suas reivindicações e como a formação de professores para a educação do campo deve ser pensada e estruturada a partir de currículos e projetos para as demandas do/no campo.

\section{Resumo 02}

Neste artigo vamos descrever a história da luta por uma vida melhor do homem do campo e uma educação do campo mais apropriada a sua realidade no Brasil, desde o tempo imperial até os dias atuais, onde podemos observar que a luta desse povo não é de hoje, é desde o descobrimento do Brasil pelos portugueses. Vamos também relatar alguns fatos que foram realizados e conquistas que aconteceram durante todos estes períodos através dos movimentos sociais especificamente do Movimento dos Trabalhadores Rurais Sem Terra (MST). Nosso objetivo é compreender tais fatos através de pesquisas bibliográficas nessa área, buscando o entendimento em relação ao posicionamento do Estado em relação às práticas educativas para os que trabalham e residem no meio rural brasileiro. Como reação a essa realidade, os movimentos sociais vem acumulando experiências de cursos de formação, em convênio com escolas normais e cursos de pedagogia, para formar educadoras e educadores capacitados a atuar na especificidade social e cultural dos povos que vivem no campo. Pretende-se ainda fornecer elementos para pesquisa e, sobretudo, para propostas de currículos dos cursos de formação, de modo a cumprirem com a responsabilidade de formar educadoras e educadores para garantir o direito à educação de qualidade para os povos do campo.

\section{Resumo 03}

O presente artigo tem por objetivo apresentar brevemente o conceito de educação do campo e analisar a formação de professores nas licenciaturas em educação do campo. O conceito de educação do campo é considerado ainda em construção. Foi desenvolvido inicialmente no interior dos movimentos sociais do campo que, a partir da pressão política no/do campo, tomou a dimensão de política pública. A licenciatura em educação do campo é uma nova modalidade de graduação nas Universidades públicas brasileiras em parceria com os movimentos sociais, em especial o MST. A organização curricular desta graduação prevê etapas presenciais ofertadas em regime de alternância entre tempo escola e tempo comunidade. O perfil do educador do campo que os movimentos demandam exige uma compreensão ampliada de seu papel. A pesquisa deve ser um processo permanente em sua vida profissional.

\section{Resumo 04}

O presente artigo tem por objetivo analisar o processo da educação do campo no Brasil e a formação de professores para a educação do campo no Brasil, visto que os povos do campo não receberam ao longo da história uma educação formal de acordo com suas necessidades e nem os professores devidamente qualificados dentro de suas especificidades. Nessa direção, houve a necessidade de organizar movimentos sociais reunindo forças, fortalecendo esse trajeto em busca de melhores condições de ensino para que permaneçam no campo, podendo cultivar suas tradições, sem serem obrigados a saírem de seu lugar de origem e vivência. É necessário formar educadores comprometidos com as lutas que homens e mulheres, que vivem e trabalham no campo, buscam através de reivindicações, na busca de respeito pela sua cultura, sua identidade, seus valores e os valores de suas terras. Constam também no texto, reflexões sobre a Educação do Campo no cenário das políticas públicas, ressaltando que a educação do campo possui uma trajetória bastante complexa que merece mais atenção. Este artigo mostra também o quanto os movimentos e organizações sociais do campo avançaram nesse processo de luta por uma educação democrática. É luta que perpassa por dificuldades, devido à imposição dos elitistas em ignorarem a maior parte da população, a população campesina. 
Por meio da análise do corpus acima, é perceptível o discurso crítico dos alunos já apresentado nos resumos dos artigos produzidos. No resumo 01 , observamos que os autores buscam demonstrar no seu texto diversas leituras sociais que podem ser realizadas pela história da educação do campo no Brasil: “[...] uma vez que esta passou a ocupar espaço no cenário educacional brasileiro, nos últimos quinze anos, através da luta constante dos movimentos sociais, principalmente com as reivindicações do MST - Movimento dos trabalhadores Sem Terra". (Resumo 01).

No resumo 02, é possível observar uma retomada do discurso apresentado pelos autores do resumo 01, porém com uma relação tempo/espaço que demarca a história da educação do campo no país: "Neste artigo vamos descrever a história da luta por uma vida melhor do homem do campo e uma educação do campo mais apropriada a sua realidade no Brasil, desde o tempo imperial até os dias atuais, onde podemos observar que a luta desse povo não é de hoje".

Sobre isso, Fischer e Pelandré (2010, p. 576) argumentam que a prática da leitura e da escrita, quando situada, permite que os alunos desenvolvam um pensar crítico e reflexivo sobre as práticas do letramento, “com o propósito de transformá-los, ao mesmo tempo em que transformam as suas próprias identidades sociais". Por meio das práticas de letramentos, os acadêmicos podem compreender o papel da leitura e da escrita para além das exigências gramaticais. Temos, nesse processo, segundo os autores, a interação dos sujeitos por meio da linguagem.

No Resumo 03, é nítida a compreensão dos autores que as reflexões sobre a educação do campo ainda estão em construção: "O conceito de educação do campo é considerado ainda em construção. Foi desenvolvido inicialmente no interior dos movimentos sociais do campo que, a partir da pressão política no/do campo, tomou a dimensão de política pública". Os trechos dos resumos demonstram o processo crítico dos alunos sobre o discurso acadêmico presente na universidade, pois muitos estudantes, conforme observações em classe, não conheciam a política da educação do campo no país, mas apenas as dimensões da educação rural.

Frente a isso, compreendemos que é importante desenvolver, nas práticas de letramento, a valorização do conhecimento prévio dos alunos sobre a leitura e escrita que percorrem seu processo de escolarização e a compreensão do contexto de produção e recepção dos textos (MARINHO, 2010). Aliado a esse pensamento, Marinho (2010, p. 384) menciona ainda que os alunos precisam compreender as relações de poder estabelecidas no discurso 
acadêmico, "de forma a não reduzir as suas dificuldades a uma suposta carência de conhecimentos linguísticos, gramaticais ou técnicos".

Por outro lado, pensar o letramento acadêmico na perspectiva sociocultural permitiu que os acadêmicos ampliassem o enfoque da leitura e da escrita como atividade que supera as dimensões das normas técnicas. Isso porque são empregados nos textos termos que direcionam a perspectiva histórica e cultural, que perpassa o processo da linguagem como prática social e situada, "isso implica o reconhecimento de múltiplos letramentos, variando no tempo e no espaço, e as relações de poder que configuram tais práticas" (STREET, 2003, p. 77). Nesse âmbito, temos a valorização do letramento acadêmico como uma prática histórica, ideológica e situada, uma vez que os acadêmicos apresentam experiências que são anteriores ao ingresso na universidade.

Ademais, é possível compreender também a dimensão científica de alguns alunos com o uso da metodologia científica: "Nosso objetivo é compreender tais fatos através de pesquisas bibliográficas nessa área, buscando o entendimento em relação ao posicionamento do Estado em relação às práticas educativas para os que trabalham e residem no meio rural brasileiro" (Resumo 02). Nesse caso, os autores compreendem e mobilizam a perspectiva metodológica na produção do trabalho, com destaque para a pesquisa bibliográfica.

No resumo 04, é perceptível o desenvolvimento linguístico dos acadêmicos sobre o objetivo do artigo: "analisar o processo da educação do campo no Brasil e a formação de professores para a educação do campo no Brasil". Nesse caso, notamos a presença do verbo "analisar" no infinitivo, que demarca, em relação ao objetivo geral da pesquisa, as produções de cunho científico tradicionalmente.

Ancorado a isso, é possível inferir a dimensão do pensamento crítico dos alunos diante do conteúdo abordado nos textos para a produção dos artigos, pois, por meio das percepções e fatos do cotidiano, os acadêmicos conseguiram redimensionar os conhecimentos apreendidos na revisão da literatura, na pesquisa bibliográfica e na construção da escrita científica, corroborando a ideia de que "os letramentos acadêmicos permitem pensar o ensino da escrita a partir de princípios transformadores que envolvem as relações que os sujeitos têm com o conhecimento e as relações de poder presentes no contexto de ensino" (FIAD, 2015, p. 29-30).

Em consonância a isso, nos discursos dos acadêmicos, é observável a necessidade da defesa dos alunos na própria escrita: "Objetivamos o entendimento e ampliação dos conhecimentos sobre a trajetória da Educação do Campo, buscando trazer informações para as comunidades dos acadêmicos do curso de educação do campo e a todos que interessarem 
ampliar seus conhecimentos" (Resumo 01); "Pretende-se ainda fornecer elementos para pesquisa e, sobretudo, para propostas de currículos dos cursos de formação, de modo a cumprirem com a responsabilidade de formar educadoras e educadores para garantir o direito à educação de qualidade para os povos do campo" (Resumo 02).

Nesse processo, podemos perceber a inserção dos alunos no processo de socialização acadêmica e a busca pela transformação social por meio da leitura e da escrita, bem como o processo de autoria, pois as práticas desenvolvidas "constroem nesses sujeitos uma consciência social que faz com que eles se percebam como parte da classe trabalhadora, com ela se identifiquem e por ela se coloquem em luta nos espaços onde vivem" (ARAUJO, 2016, p. 135). Sendo assim, inferimos que a elaboração do artigo científico exigiu deles o desenvolvimento de habilidades da leitura e da escrita, bem como a compreensão da leitura de mundo (FREIRE, 1989).

Em outras palavras, as práticas de letramento acadêmico vivenciadas pelos alunos exigiram, ainda, a compreensão da linguagem como processo de poder e construção de identidades sociais (BEZERRA, 2012). Consequentemente, nas atividades, os acadêmicos foram direcionados a analisar e construir o texto acadêmico como domínios discursivos, ideológicos e formadores de conhecimento, em particular com o movimento da reescrita textual que exigiu dos alunos maior atenção e cuidado com a produção do trabalho final a ser apresentado.

Acreditamos que o desenvolvimento da experiência despertou nos acadêmicos a necessidade do olhar reflexivo e crítico para a produção do artigo científico e demais gêneros acadêmicos. Com essa dinâmica, os estudantes conheceram diversas concepções teóricas e metodológicas sobre os gêneros trabalhados, bem como o contexto de produção e recepção do gênero acadêmico artigo científico, pois "a escrita do aluno é uma prática social complexa, que requer dos estudantes mais do que o domínio de habilidades de estudo ou a socialização no ambiente acadêmico" (BEZERRA, 2012, p. 251).

A experiência proporcionou aos acadêmicos a compreensão da leitura e da escrita acadêmica não como mera exigência da universidade, mas sim como situações comunicativas, socioculturais e ideológicas. Por um lado, muitos alunos questionaram o próprio modo de compreender a leitura e a escrita. Por outro lado, discutiram as possibilidades e dificuldades dessas práticas como ações socioculturais e formativas. No caso do professor, é possível afirmar que essa experiência despertou a necessidade de propor ações de letramento que superem as dimensões prescritas da língua. Acrescido a isso, as atividades desenvolvidas em 
classe apontaram para a revisão e valorização permanente dos saberes e identidade dos estudantes.

\section{CONSIDERAÇÕES FINAIS}

As atividades empreendidas nos permitem analisar que a prática da leitura e da escrita no ensino superior vai além das regras das normas técnicas, pois constitui também em emancipação humana, desenvolvimento crítico e intelectual. Logo compreendemos, com base nesses dados, que "ficam as evidências na tentativa de provocar mudanças, de construir outros sentidos às práticas letradas no meio acadêmico" (FISCHER, 2008, p. 187).

Entendemos que o letramento acadêmico, além de ser um processo de produção da leitura e da escrita no ensino superior, precisa ser compreendido também - tanto pelos alunos quanto por professores - como ação discursiva e social que permite a formação de novos saberes, a construção de identidades sociais e/ou a legitimação de poder de um grupo específico.

Sendo assim, a experiência demonstrou que a leitura e a escrita são práticas complexas e ideológicas, pois, dependendo do contexto, ocorrem processos de reconfiguração, estruturas e modelos discursivos que são na maioria das vezes determinantes na legitimação de uma ideia ou defesa de opinião. Para maior compreensão e efetivação de atividades de letramentos acadêmicos com base nos dados obtidos, acreditamos que seja necessário maior empenho dos acadêmicos e docentes no desenvolvimento de novas atividades sobre a função social e científica da produção escrita.

\section{REFERÊNCIAS}

ARAUJO, C. Discursos que revelam o letramento acadêmico na (RE) constituição identitária dos educandos da licenciatura em Educação do Campo. Dissertação (Mestrado em Linguística) - Universidade de Brasília, Brasília, 2016.

BAKHTIN, M. Marxismo e Filosofia da Linguagem. Tradução de Michel Lahud e Yara F. Vieira. São Paulo: Editora Hucitec, 1986.

Estética da Criação Verbal. São Paulo: Martins Fontes, 2003.

BEZERRA, B. Letramentos Acadêmicos na Perspectiva dos Gêneros Textuais. Fórum Linguístico, Florianópolis, v. 9, n. 4, p. 247-258, out./dez. 2012.

BRITTO, L. P. Leitura e escrita de estudantes universitários. In: Contra o consenso. Cultura escrita, educação e participação. Campinas, SP, Mercado de Letras, 2003. 
CONNELly, F. M; CLANDININ, D. J. Pesquisa narrativa: experiência e história em pesquisa qualitativa. Tradução: Grupo de Pesquisa Narrativa e Educação de Professores ILEEI/UFU. Uberlândia: EDUFU, 2015.

FIAD, R. S. Algumas considerações sobre os letramentos acadêmicos no contexto brasileiro. Pensares em revista, São Gonçalo - RJ, nº 6, jan/jun, 2015, p. 23-34.

FISCHER, A. Letramento acadêmico: uma perspectiva letramento portuguesa. Acta Sci. Lang. Cult. Maringá, v. 30, n. 2, p. 177-187, 2008.

FREIRE, P. A importância do ato de ler: em três artigos que se completam. São Paulo: Autores Associados: Cortez, 1989.

GEE, J. P. Social linguistics and literacies: ideology in discourses. 2 ed. Lond: The Farmer Press, 1999.

TFOUNI, L.V. Letramento e alfabetização. São Paulo: Cortez, 1995.

KLEIMAN, A. B. Os estudos de letramento e a formação do professor de língua materna. Linguagem em (dis)curso - LemD, v. 8, n. 3, p. 487-517, set./dez, 2008a. $\overline{61,2008 .}$

(2008b). Modelos de letramento e as práticas de alfabetização na escola, pp. 15-

LEA, M. R; STREET. B. V. Student writing in higher education: an academic literacies approach. Studies in Higher Education, Jun 98, Vol. 23 Issue 2, p157, 16p, 1998.

MARCUSCHI, L. A. A oralidade e letramento. In: retextualização. $8^{\mathrm{a}}$ ed. São Paulo: Cortez, Cap. 1, p. 15-43, 2007.

Da fala para a escrita: atividade de . Gêneros textuais definição e funcionalidade. In: DIONÍSIO, A. P.; MACHADO, A. R.; BEZERRA, M. A (Org.). Gêneros textuais e ensino. Rio de Janeiro: Lucerna, p. 19-36, 2002.

MARINHO, M. A escrita nas práticas de letramento acadêmico. RBLA, Belo Horizonte, v. 10, n. 2, p. 363-386, 2010.

ORTEGA, L. P; DINIZ, P. A. Como se constitui a aula enquanto gênero discursivo. In: Ferreira, N. S. A et al. (Org.) Anais do $1^{\circ}$ COLE - Congresso de Leitura do Brasil. Campinas-SP: Gráfica FÉ; ALB, 2005.

SANTOS, D. O. B. Letramento acadêmico. Representações de ingressantes acerca da escrita. Revista Trama, Cascavel v. 13, no 28, 2017, p. 86-118.

SOARES, M. B. Alfabetização e letramento: caminhos e descaminhos. Pátio, n. 29, fev. 2004. Disponível em: <http://pt.scribd.com/doc/18892732/Artigo-Alfabetizacao-eLetramentoMagda-Soares1>. Acesso em: 20 de maio de 2014. 
SOUZA, M. A. Educação do campo: propostas e práticas pedagógicas do MST. Petrópolis: Vozes, 2006.

STREET, B. V. Letramentos sociais: abordagens críticas do letramento no desenvolvimento, na etnografia e na educação. Trad. Marcos B. São Paulo: Parábola, 2014.

What's "new" in New Literacy Studies? Critical approaches to literacy in theory and practice. Current Issues in Comparative Education. Comlumbia: Teachers College, Columbia Univesity, vol. 5 (2), p. 77-91, 2003.

UNIVERSIDADE FEDERAL DO TOCANTINS - UFT. Projeto Pedagógico do Curso de Licenciatura em Educação do Campo - PPC, 2014.

\section{O AUTOR}

Sebastião Silva Soares é professor assistente no Curso de Educação do Campo, da Universidade Federal do Tocantins (UFT) - Campus Arraias, doutorando em Educação pela Universidade Federal de Uberlândia (UFU) e Mestre em Educação pela Universidade de Brasília (UnB).

E-mail: sebastiaokenndy@yahoo.com.br 